\title{
Circuit
}

Musiques contemporaines

\section{The Concert Accordion : Contemporary Perspectives, de Joseph Petrič, Essen, Augemus Musikverlag, 2017, 321 pages}

\section{Réjean Beaucage}

Volume 28, numéro 3, 2018

URI : https://id.erudit.org/iderudit/1055200ar

DOI : https://doi.org/10.7202/1055200ar

Aller au sommaire du numéro

\section{Éditeur(s)}

Circuit, musiques contemporaines

ISSN

1183-1693 (imprimé)

1488-9692 (numérique)

Découvrir la revue

Citer ce compte rendu

Beaucage, R. (2018). Compte rendu de [The Concert Accordion : Contemporary Perspectives, de Joseph Petrič, Essen, Augemus Musikverlag, 2017, 321 pages]. Circuit, 28(3), 96-97. https://doi.org/10.7202/1055200ar

Ce document est protégé par la loi sur le droit d'auteur. L’utilisation des services d’Érudit (y compris la reproduction) est assujettie à sa politique d'utilisation que vous pouvez consulter en ligne.

https://apropos.erudit.org/fr/usagers/politique-dutilisation/
Cet article est diffusé et préservé par Érudit.

Érudit est un consortium interuniversitaire sans but lucratif composé de l’Université de Montréal, l’Université Laval et l’Université du Québec à Montréal. Il a pour mission la promotion et la valorisation de la recherche. https://www.erudit.org/fr/ 


\section{The Concert Accordion: Contemporary Perspectives, de Joseph Petrič}

Essen, Augemus Musikverlag, 2017, 321 pages.

Compte rendu de Réjean Beaucage

Dès le tout premier paragraphe, l'auteur nous prévient: il est obsédé par son sujet et, n'eût été l'absence de cheminement scolaire destiné à l'apprentissage de l'accordéon, constatée alors qu'il avait 12 ans, il n'aurait sans doute pas écrit ce livre. On a donc entre les mains le résultat d'un manque qui cherche à être comblé, doublé d'un réquisitoire contre les tenants d'un positivisme qui se serait développé chez nombre d'accordéonistes à partir des années 1960 et aurait délibérément cherché à oblitérer la riche histoire du développement de l'instrument.

Une histoire riche, en effet, et l'auteur nous rappelle qu'au début du xx siècle, pendant que Max Planck développait la théorie des quantas, que Sigmund Freud publiait L'interprétation des rêves ou qu'Einstein déterminait qu'E $=\mathrm{mc}^{2}$, Giovanni Gagliardi, lui, lançait son Petit manuel de l'accordéoniste! Blague à part, et outre quelques comparaisons douteuses de ce type, le livre de Petrič est le fruit d'une recherche importante, mal- très techniques de fabrication et des réflexions sur l'art de l'interprétation, dont la forme la plus achevée est le palimpseste, une réécriture créative dont les accordéonistes, à travers les nombreuses œuvres du répertoire adaptées pour leur instrument, auraient le secret. Dans ce compendium qui n'est ni chronologique, ni géographiquement linéaire, on va de l'invention par Cyrill Demian (1772-1847) des premiers modèles d'accordéon jusqu'à l'expérience personnelle de l'auteur (qui est certainement le plus connu des accordéonistes cana-

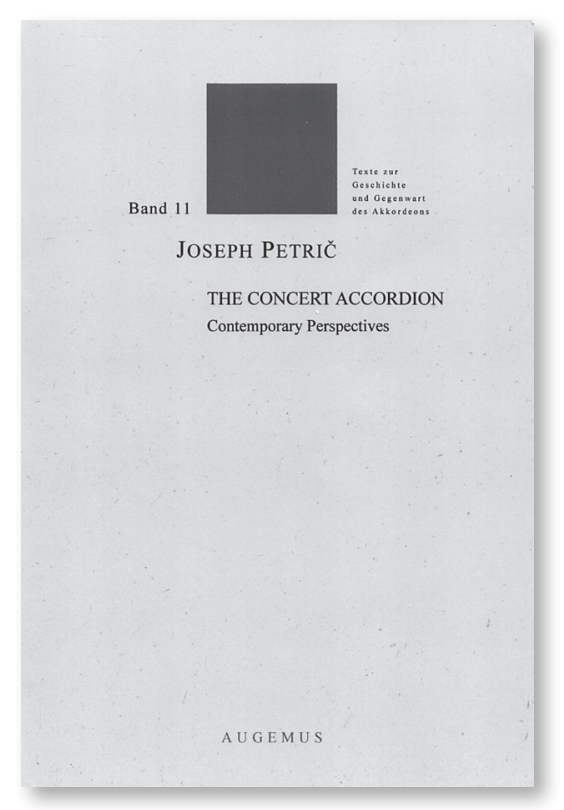


diens), en passant par les multiples développements de la famille des accordéons en Italie, puis dans toute l'Europe et enfin en Amérique du Nord. C'est sur ce continent, et en partie grâce aux accordéonistes, que s'est développée une qualité supérieure d'intertextualité musicale: «Americans loved the old, they loved the new, and they loved both at the same time. They were a palimpsestuous lot» (p. 104).

Le livre contient également des listes d'œuvres que l'accordéoniste pourrait vouloir transcrire pour son instrument, mais est-il bien utile de faire la liste de toutes les pièces de Rameau, de Bach ou de Couperin (entre autres!) qui pourraient faire l'objet de transcriptions? On trouve aussi une liste impressionnante, et plus utile, d'œuvres contemporaines pour accordéon ayant été créées par l'auteur. Il y a la matière de plusieurs essais dans ces 300 pages, ce qui en fait un ouvrage hétéroclite et touffu, dont le texte souffre d'un manque d'organisation, mais s'appuie néanmoins sur une recherche solide.

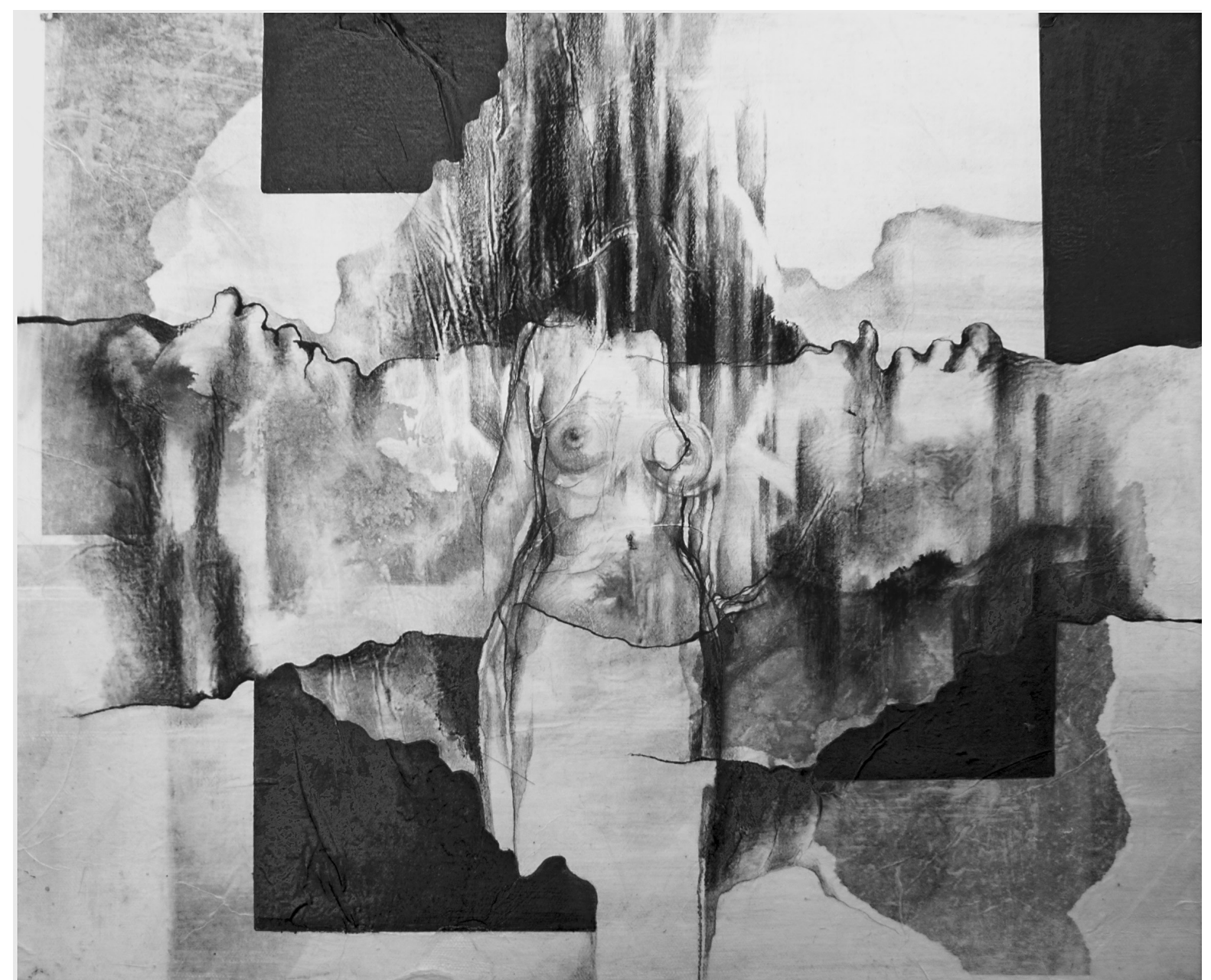

